\title{
Malaria and antioxidants: beware
}

\section{Introduction}

Plasmodium generates an oxidant stress in the infected persons, which is a defense mechanism of the human organism against the parasites, but at the same time generated by the parasite itself. The digestion of hemoglobin, an essential process for blood-feeding parasites, generates heme and oxygen radicals. The parasite eliminates heme by crystallizing it into hemozoin. Most antimalarials, especially artemisinin, attack the parasite by an oxidative process. An excess of oxidants however is inflammatory. Many constituants of our nutrition temper this harmful effect but are also antagonistic with therapeutic effect of oxydants.

\section{The difficult balance between oxidants and antioxidants}

Green tea Camellia sinensis has no antimalarial properties. No paper can be found in the scientific literature documenting such a property. And the studies of Mutaz Akkawi have shown that green tea does not inhibit hemozoin like Artemisia annua or afra or sieberi do. Strange! Camellia sinensis compared with other medicinal plants is very rich in polyphenols and catechins. Mentha piperata is at the same high level and no documents concerning any antimalarial property of this plant can be found either. For both plants the total polyphenol concentration is 4 times higher than for plants with known antimalarial properties and strong beta-hematin inhibition like Salvia, Ocimum. Antioxidant capacity is strongly correlated with polyphenol content (Figure 1).

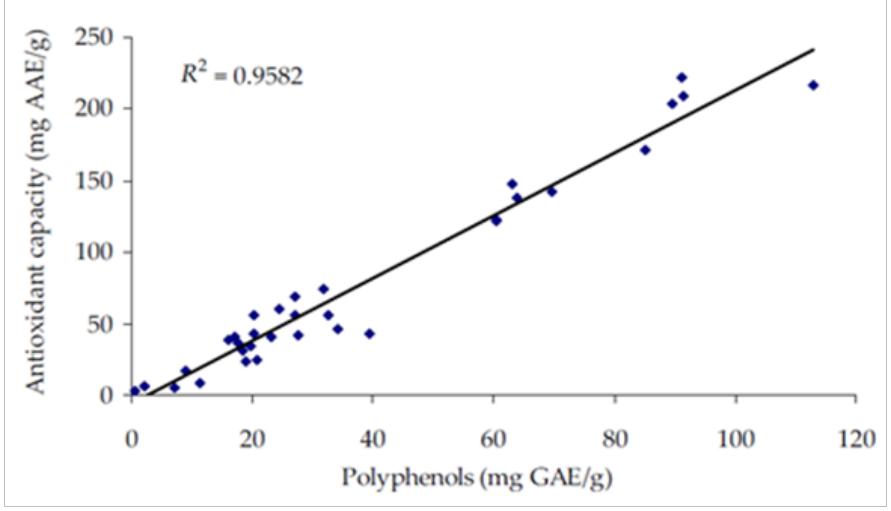

Figure I Correlation between total phenolic content and antioxidant capacity of herbs.'

Papers which compare the polyphenol content of Artemisia plants with other medicinal plants are scarce. A paper from Croatia finds for Artemisia absinthium values which are again at least 4 times lower than for Mentha piperata. ${ }^{2}$ Another paper gives similar results for the lipid peroxidation and total phenolic content of Artemisia absinthium compared to other medicinal plants. ${ }^{3}$ Almost 10 years ago we had a program with the University of Louvain and Celabor at Herve. They were looking for antioxidant molecules to be used in the food industry and expected to find strong antioxidant properties in Artemisia annua. Their disappointment was great (report available) and they canceled their research project. The Plasmodium infected erythrocyte is under constant oxidative stress. This is caused by reactive oxidant species (ROS) and reactive nitrogen species (RNS) produced by the immune system of the host, and by production of ROS generated during
Volume 6 Issue 5 - 2018

\author{
Pierre Lutgen,' Jerôme Munyangi² \\ 'IFBV-BELHERB, Luxembourg \\ ${ }^{2}$ University of Kolwezi, Democratic Republic of Congo
}

Correspondence: Pierre Lutgen, IFBV-BELHERB, BP 98 L-6905, Niederanven, Luxembourg, Email lutgenp@gms.lu

Received: August II, 2018 | Published: September 05, 2018

digestion of hemoglobulin. The parasite is killed by oxidation, and the efficacy of the peroxide artemisinin is the best proof of this. To minimize the damage caused by reactive radicals, antioxidant enzymes and their substrates found in parasites and in erythrocyte Plasmodium falciparum synthesizes its own vitamin E. ${ }^{4}$ Supplementation with food containing vitamin E may even increase transmission from infected vertebrate to mosquitoes (Figure 2).

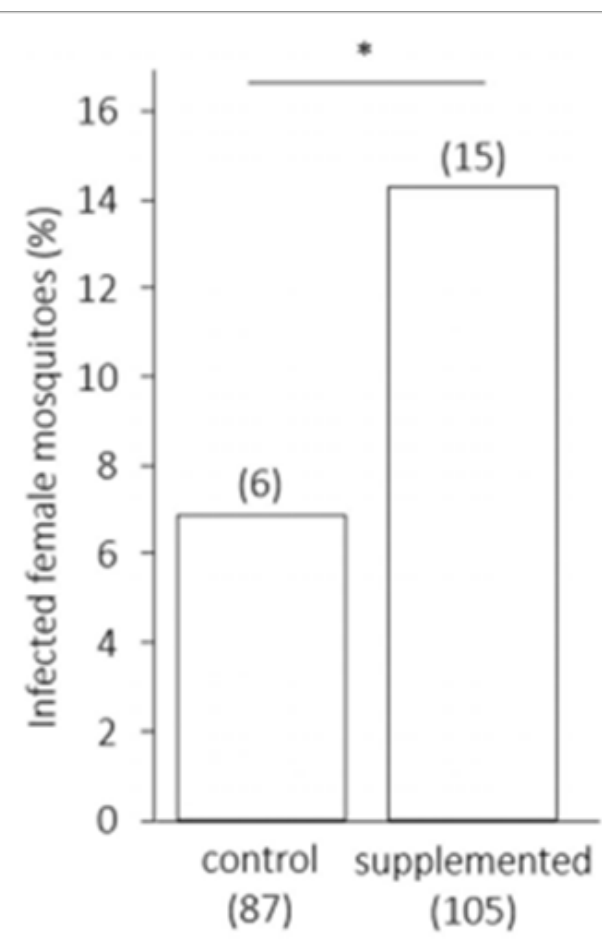

bird antioxidant treatment

Figure 2 Prevalence of infected female mosquitoes (percent, \%) as a function of the antioxidant treatment of the infected bird host. Sample sizes are given in brackets below each bar: the number of fed females and above each bar: the number of infected females. A star indicates a significant difference. ${ }^{5}$

Worse even, vitamin E supplementation triggers the development of cerebral malaria and it breaks down the blood-brain barrier. Tocopherol (vitamin E) deficiency in the circulation prevents cerebral malaria. Feeding a pro-oxidant diet containing fish oil, but devoid of vitamin E, protects mice against malaria parasites and improves survival in cerebral malaria. Unsaturated fatty acids strongly suppress 
the strong antioxidant vitamin $\mathrm{E}$ which protects Plasmodia against oxidative stress. Artemisia annua leaves contain up to $10 \%$ of fatty acids in dry matter. ${ }^{6-9}$ Modulation of redox homeostasis and the synergism between pro- and antioxidants is also an important factor in the formation of gametocytes. ${ }^{10}$ This confirms many statements and claims I have made in my publications. Plasmodium falciparum is not killed by the supposedly high antioxidant properties of Artemisia but because this herb is poor in antioxidants. This may also explain why other medicinal plants, like Neem or Moringa, famous for their antioxidant capacity have no antimalarial properties. And why Artemisia vulgaris, Artemisia dracunculus and Artemisia princeps have no antimalarial properties. They are rich in Vitamin $\mathrm{C}$ and Artemisia vulgaris is rich in 3,5-caffeeoylquinic acid, a high molecular weight polyphenol. Rats treated with a dose of $100 \mathrm{mg} / \mathrm{kg}$ with aqueous extract of Artemisia vulgaris see their serum ascorbic acid increase from 3.58 to $6.30 \mathrm{mg} / \mathrm{L} .^{11,12}$

Artemisia annua is very poor in catechins and mixing with other plants rich in catechins (moringa, green tea) might have antagonistic effects. ${ }^{13,14}$ But many of these plants have prophylactic properties, probably because of this high vitamin $\mathrm{C}$ content, like grapefruit juice or papaya. Vitamin C stimulates humoral immunity through increased antibody synthesis particularly $\operatorname{IgG}, \operatorname{IgA}$, IgM and also activating the macrophages. ${ }^{15,16}$ The strong belief which almost became a myth, that flavonoids and polyphenols play a key role in the antimalarial properties is based on a paper from 1992 which has been quoted in many subsequent works. Looking at it closely it appears that the flavonoids have IC50 properties which are 1000 times weaker than for artemisinin and the potentiation of the antimalarial role of artemisinin is only marginal. And the authors wisely state that their in vitro study is an unproved possibility and needs to be confirmed by in vivo clinical studies. But the belief had become a dogma and the flavonoids overshadowed other essential molecules in Artemisia: pentacyclic triterpenes, scopoletin, phytosterols, polyunsaturated fatty acids, amino acids, anthocyanins, proanthocyanidins, polysaccharides, taurine, minerals, salts. ${ }^{17,18}$ Furthermore, these polyphenols are extensively metabolized in humans. And the in vivo contribution of polyphenols might be lower than expected from the in vitro tests. ${ }^{19,20}$ An USDA study (EA Brisibe op.cit.) has made probably the most complete analysis of constituents of Artemisia annua. The concentration in vitamins in the different tissues of the sundried plant materials was investigated. Vitamin $\mathrm{E}$ was detected with the highest levels in the leaves $22.63 \mathrm{mg} / \mathrm{kg}$ vs only $1.19 \mathrm{mg} / \mathrm{kg}$ in the stems. This to a large extent explains the differences in antioxidant capacity which is 4times higher for leaves than for stems. Vitamin $\mathrm{E}$ is one of the strongest antioxidants. A similar result was found in a study concerning Artemisia montana harvested at different development stages from June to October in Korea. Flavonoids are only found in leaves and are always absent in stems. ${ }^{21}$

There are many anecdotic reports indicating that including stems and twigs with dried Artemisia leaves augments the power of the infusion. Operators of palm oil plant in Burundi only drink infusions made with stems and stay malaria free. Along the same lines there is ample documentation in the scientific literature that sun drying or boiling (decoction) destroys vitamins $\mathrm{C}$ almost completely, vitamin $\mathrm{E}$ less. Sun-drying for three weeks decreases the antioxidant power by $95 \%$, shade drying only by $70 \%$. It is thus recommended to use sun dried herb for malaria control, not fresh, green leaves and to prepare decoctions rather than infusions. ${ }^{22-24}$ Antioxidants may be important in fighting other diseases but not malaria. Although this panacea is heavily questioned now. ${ }^{25}$ Randomized clinical trials failed to validate the claim that vitamin $\mathrm{E}$ lowers the risk of cancer and its mortality. Vitamin E can interfere with the action of other chemotherapeutic agents. Vitamin E may increase the risk of hemorrhagic stroke. Vitamin E supplementation may increase overall mortality.

\section{Acknowledgements}

None.

\section{Conflict of interest}

The author declares that there is no Conflict of interest.

\section{References}

1. Diana Chrpová, Lenka Kouřimsk, Michael Harry Gordon. Antioxidant Activity of Selected Phenols and Herbs Used in Diets for Medical Conditions. Czech J Food Sci. 2010;28(4):317-325.

2. Katalinic V, Milos M, Kulisic T, et al. Screening of 70 medicinal plant extracts for antioxidant capacity and total phenols. Food Chemistry. 2004;94(4):550-557.

3. Sharareh Rezaeian, Hamid Reza Pourianfar, Javad Janpoor. Antioxidant properties of several medicinal plants growing wild in northeastern Iran. Asian Journal of Plant Science and Research. 2015;5(2):63-68.

4. Rodrigo AC Sussmann, Wesley LF, Emilia AK, et al. Plasmodium falciparum uses vitamin E to avoid oxidative stress. Parasites \& Vectors. 2017; 10:461

5. Delhaye J, Glaizot O, Christe P. The effect of dietary antioxidant supplementation in a vertebrate host on the transmission of avian malaria to the vector. Parasitol Res. 2018;117(7):2047-2052.

6. Brisibe EA, Ferreira FS Xianli Wu, et al. Nutritional characterisation and antioxidant capacity of different tissues of Artemisia annua L. Food Chemistry. 2009;115(4):1240-1246.

7. Herbas MS, Okazaki M. Tocopherol transfer protein inhibition is effective in the prevention of cerebral malaria in mice. Am J Clin Nutr. 2010;91(1):200-207.

8. Levander OA, Fontela R, Morris VC, et al. Protection against Murine Cerebral Malaria by Dietary-Induced Oxidative Stress. The $J$ Parasitol. 1995;81(1):99-103.

9. Levander OA, Ager AL. Malarial parasites and antioxidant nutrients. Parasitology. 1993;107 Suppl:S95-S106.

10. Coertzen D, Reader J, Gibhard L, et al. Artemisone and Artemiside are potent panractive antimalarial agents also synergize redox imbalance in Plasmodium falciparum transmissible gametocyte stages. Antimicrob Agents Chemother. 2018;62(8):e2214-17.

11. Heitz A, Carnat A, Fraisse D, et al. Major dicaffeoylquinic acids from Artemisia vulgaris. Fitoterapia. 2000;71(5):587-589.

12. Temraz A, Tantawy W. Characterization of antioxidant activity of extract from Artemisia vulgaris. Pak J Pharm Sci. 2008;21(4): 321-326.

13. Budiman I, Rahardja F, Fauziah N. Antioxidant and anti-malarial properties of catechins. British Journal of Medicine and Medical Research. 2015;5(7):895-902.

14. Jae Kyeom, Eu-Cheol Shin. Characterization of Nutritional Composition, Antioxidative capacity of Semae Mugwort, a native Korean Artemisia. $J$ Anal Methods Chem. 2015;2015:916346.

15. Oreagba AI, Aina OO, Awodele O, et al. Prophylactic effect of grapefruit juice against Plasmodium berghei Infection in mice. Int $J$ Pharmacol. 2008;4(1):60-63. 
16. Ansari KU, Pandey RC. An experimental and clinical evaluation of immunomodulating potential of ascorbic acid. Indian J Pharmacol. 1998;30(2):94-96.

17. Liu KC, Yang SL, Roberts MF, et al. Antimalarial activity of Artemisia annua flavonoids from whole plants. Plant Cell Rep. 1992;11(12):637640 .

18. Sasha WE, David EZ, Lena Struwe. Medicinal plants of Cental Asia: Uzbekistan and Kyrgiztan. Newyork: Springer Science \& Business Media; 2 acol. 2014;151(2):858-863.

19. Kim YJ, Lee JH, Kim SJ. Cultivation characteristics and flavonoid contents of wormwood (Artemisia montana). Journal of Agricultural Chemistry and Environment. 2013;2(4):117-122.
20. Ferreira JF, Luthria DL. Drying affects artemisinin, dihydroartemisinic acid, artemisinic acid and the antioxidant capacity of Artemisia annua leaves. J Agric Food Chem. 2010;58(3):1691-1698.

21. Eitenmiller R, Lee J. Vitamin E: Food Chemistry, Composition and Analysis. Boca Rotan: CRC Press; 2004. 540 p.

22. Ojike O, Nwoke OO, Okonkwo WI. The influence of different solar drying systems on the vitamin content of Pawpaw (carica papaya). Australian Journal of Agriculture Engineering. 2011;2(1):8-11.

23. Cassileth BR. Vitamin E: Oncology. 2010;24:7. 